\title{
Prevalence of multiple risk factors for poor outcomes associated with COVID-19 among an elderly Australian population
}

NL Pratt, LM Kalisch Ellett, AQ Andrade, VT Le Blanc, J Barratt, EE Roughead

\section{Background and objective Increasing age, male sex and various chronic conditions have been identified as important risk factors for poor outcomes from COVID-19. The aim of this study was to examine the prevalence of risk factors for poor outcomes due to COVID-19 infection in an older population.}

\section{Methods}

The proportion of the population with one or more risk factors and the prevalence of individual risk factors and multiple risk factors were calculated among Department of Veterans' Affairs (DVA) clients aged $\geq 70$ years.

\section{Results}

There were 103,422 DVA clients included. Of these, $79 \%$ in the community and $82 \%$ in residential aged care had at least one risk factor for poor outcomes from COVID-19. Hypertension was most prevalent, followed by chronic heart and airways disease. Over half had $\geq 2$ risk factors, and one in five had $\geq 3$ risk factors across multiple body systems.

\section{Discussion}

A substantial proportion of older Australians are at risk of poor outcomes from COVID-19 because of their multimorbid risk profile. These patients should be prioritised for proactive monitoring to avoid unintentional harm due to potential omission of care during the pandemic.
COLLECTIVE EFFORTS WORLDWIDE have focused on the identification of people at highest risk of poor outcomes if they contract COVID-19. Descriptive and observational studies of patients with COVID-19 in China, Italy, Spain and the USA have identified individual risk factors for poor outcomes from COVID-19. Poor outcomes include the need for hospitalisation, intensive care unit admission, intensive ventilation and death. Identified risk factors include increasing age, male sex, hypertension, ${ }^{1-8}$ chronic heart disease, ${ }^{1-8}$ diabetes, ${ }^{1-9}$ chronic airways disease, ${ }^{2-8}$ cerebrovascular disease, ${ }^{1,2,5,10}$ chronic liver disease, ${ }^{7}$ chronic renal failure, ${ }^{2,4,6-8}$ malignancy ${ }^{1,2,5,6,8,11}$ and having a suppressed immune system or being otherwise immunocompromised. ${ }^{7}$ While individual morbidities have the potential to heighten risk, comorbidities, particularly across multiple body systems, have the potential to make people increasingly vulnerable. In addition to a higher case fatality rate in individuals with comorbidities, ${ }^{4,8}$ these patients are also at high risk of harm due to gaps of care and lack of access to healthcare resources to manage their existing conditions.

The aim of this study was to determine the prevalence of these risk factors in an older Australian population and, in particular, the prevalence of multiple concurrent risk factors.

\section{Methods}

The data source for this study was the Australian Government Department of Veterans' Affairs (DVA) health claims data. The DVA claims dataset includes details of all service-related disabilities, claims for pharmacy and primary care medical services, and hospitalisation (both public and private) and allied health service claims provided to DVA clients (including eligible veterans, spouses and dependents) that are subsidised by the DVA. Medications are coded in the dataset according to the World Health Organization (WHO) Anatomical and Therapeutic Chemical Classification, ${ }^{12}$ while primary care services are coded according to the Medicare Benefits Schedule (MBS) ${ }^{13}$ and DVA schedule of fees. ${ }^{14}$ Hospital admissions are coded according to the International statistical classification of diseases and related health problems, 10th revision, Australian modification (ICD-10-AM) ${ }^{15}$ Patients were included in this study if they were aged $\geq 70$ years as at 1 April 2020 and were full DVA entitlement card holders (ie eligible for all healthcare services). Patients aged $\geq 70$ years were included as this age was identified as an important threshold for increased risk of case fatality rates in Italy and Spain ${ }^{1}$ and in-hospital mortality. ${ }^{16}$ Patients who had died prior to April 2020 were excluded. Medicines dispensed, MBS services 
claimed and hospital admissions were used to determine the prevalence of the comorbidities associated with poorer outcomes in the event of COVID-19 infection. Phenotypes were created for hypertension, chronic heart disease (including heart failure, ischaemic heart disease), diabetes, chronic airways disease (including asthma and chronic obstructive pulmonary disease [COPD]), cerebrovascular disease, chronic liver disease, chronic renal failure, recent malignancy and a suppressed immune system. The researchers examined medicine use in the latest year and hospital events within the preceding five years for all risk factors except recent cancer treatment and dialysis, for which the latest year of data available was used. Full details of the codes used to determine each phenotype are shown in Table 1.

To identify the prevalence of multiple risk factors across multiple body systems, the researchers grouped the related conditions of hypertension, cardiovascular disease and cerebrovascular diseases into one category, as they all affect the

\section{Table 1. Medication and hospitalisation codes used to identify each risk factor}

\begin{tabular}{|c|c|c|c|}
\hline $\begin{array}{l}\text { Body system } \\
\text { group }\end{array}$ & Risk factor & $\begin{array}{l}\text { Indicator medications or hospital } \\
\text { diagnoses }\end{array}$ & $\begin{array}{l}\text { Codes used to identify indicator } \\
\text { medications or hospital admissions for } \\
\text { conditions }\end{array}$ \\
\hline \multirow[t]{6}{*}{ Cardiovascular } & \multirow[t]{2}{*}{ Hypertension } & \multirow{2}{*}{$\begin{array}{l}\text { Angiotensin-converting enzyme } \\
\text { and angiotensin receptor blockers, } \\
\text { thiazides, beta-blockers (excluding } \\
\text { those subsidised for heart failure), } \\
\text { calcium channel blockers, other } \\
\text { antihypertensive medication or } \\
\text { hospitalisation for hypertensive } \\
\text { heart disease }\end{array}$} & $\begin{array}{l}\text { ATC codes: C09, C02, C03AA, C08, } \\
\text { metoprolol succinate (PBS item codes: } \\
\text { 08732N, 08733P, 08734Q, 08735R) and C07 } \\
\text { (excluding medications used for heart failure, } \\
\text { namely carvedilol [C07AG02] and bisoprolol } \\
\text { [C07AB07]) }\end{array}$ \\
\hline & & & ICD-10-AM codes: I10-I15 \\
\hline & \multirow{3}{*}{$\begin{array}{l}\text { Chronic heart disease, } \\
\text { including heart failure, } \\
\text { ischaemic heart disease }{ }^{1-7}\end{array}$} & \multirow{3}{*}{$\begin{array}{l}\text { Medications for heart failure } \\
\text { (carvedilol, bisoprolol, metoprolol } \\
\text { succinate, ivabradine, epleronone) or } \\
\text { atrial fibrillation (direct-acting oral } \\
\text { anticoagulants); hospitalisation for } \\
\text { congestive heart failure; ischaemic } \\
\text { heart disease; or atrial fibrillation }\end{array}$} & $\begin{array}{l}\text { ATC codes: C07AG02, C07AB07, C01EB17, } \\
\text { C03DA04 }\end{array}$ \\
\hline & & & $\begin{array}{l}\text { PBS item codes: 08732N, 08733P, 08734Q, } \\
\text { 08735R, 02769R, 92457E, 02753X, 02268J, } \\
\text { 02691P, 02735Y, 02744K }\end{array}$ \\
\hline & & & ICD-10-AM codes: I20-I25, I50, I48 \\
\hline & $\begin{array}{l}\text { Cerebrovascular } \\
\text { disease }^{2,3,6,8}\end{array}$ & $\begin{array}{l}\text { Hospitalisation for ischaemic or } \\
\text { haemorrhagic stroke }\end{array}$ & ICD-10-AM codes: I61, I63, I64 \\
\hline \multirow[t]{2}{*}{ Diabetes } & \multirow[t]{2}{*}{ Diabetes $^{1-8}$} & \multirow{2}{*}{$\begin{array}{l}\text { Medications or hospitalisation for } \\
\text { diabetes }\end{array}$} & ATC codes: A10 \\
\hline & & & ICD-10-AM codes: E10-E14 \\
\hline \multirow[t]{2}{*}{ Respiratory } & \multirow{2}{*}{$\begin{array}{l}\text { Chronic airways disease } \\
\text { (including asthma and } \\
\text { chronic obstructive } \\
\text { pulmonary disease) }{ }^{2-7}\end{array}$} & \multirow{2}{*}{$\begin{array}{l}\text { Long-acting beta agonists, muscarinic } \\
\text { antagonists alone or in combination, } \\
\text { or hospital admission for chronic lower } \\
\text { respiratory tract diseases, pneumonia } \\
\text { or influenza }\end{array}$} & $\begin{array}{l}\text { ATC codes: R03AC12, R03AC13, R03AC18, } \\
\text { R03BB, R03AK, R03AL }\end{array}$ \\
\hline & & & ICD-10-AM codes: J \\
\hline Liver & Chronic liver disease ${ }^{7}$ & $\begin{array}{l}\text { Hospitalisation for chronic liver } \\
\text { disease }\end{array}$ & $\begin{array}{l}\text { ICD-10-AM codes: K703, K704, K721, K729, } \\
\text { K717, K74, E830 }\end{array}$ \\
\hline Renal & Chronic renal failure $2,4,6,7$ & $\begin{array}{l}\text { Hospitalisation for chronic kidney } \\
\text { disease or kidney dialysis }\end{array}$ & ICD-10-AM codes: N18, Z49 \\
\hline \multirow[t]{4}{*}{ Immune } & \multirow{3}{*}{$\begin{array}{l}\text { Current cancer treatment, } \\
\text { malignancy }{ }^{1,2,5,6,9}\end{array}$} & \multirow{3}{*}{$\begin{array}{l}\text { Hospitalisation for neoplasms, } \\
\text { services for radiotherapy, claims for } \\
\text { cytotoxic medications }\end{array}$} & ATC codes: L01 \\
\hline & & & ICD-10-AM codes: C1-C9, Z51, \\
\hline & & & $\begin{array}{l}\text { MBS codes: } 015100,015103,015275,015555, \\
015565,015715\end{array}$ \\
\hline & $\begin{array}{l}\text { Suppressed immune } \\
\text { system or otherwise } \\
\text { immunocompromised }\end{array}$ & $\begin{array}{l}\text { Cytokine inhibitors; tumour necrosis } \\
\text { factor-a, interleukin inhibitors, } \\
\text { systemic corticosteroids, conventional } \\
\text { immunosuppressants, other biologics } \\
\text { with immunomodulating effects }\end{array}$ & ATC codes: H02AB, L04 \\
\hline
\end{tabular}

ATC, Anatomical Therapeutic Chemical; ICD-10-AM; International statistical classification of diseases and related health problems, tenth revision, Australian modification; MBS, Medicare Benefits Schedule; PBS, Pharmaceutical Benefits Scheme 
cardiovascular system and can often be treated by similar medicines. The researchers also grouped current cancer treatment and immunosuppressant use to create one category, with the remaining categories classified as individual morbidities. The one-year prevalence of use of medicines for anxiety, depression and dementia was calculated using the RxRisk comorbidity score. ${ }^{17}$ These conditions were considered to determine the potential baseline mental health and cognitive status of the individuals. The RxRisk comorbidity score identifies conditions on the basis of medicines that patients are dispensed to treat the condition over a 12-month period. The cohort was stratified by current living status: living in the community or a residential aged care (RAC) facility. Descriptive statistics were reported, including frequencies.

Ethics approval was obtained from the Department of Defence and Veterans' Affairs Human Research Ethics (E016-007) and University of South Australia Human Research Ethics (P203/04) committees.

\section{Results}

There were 103,422 people aged $\geq 70$ years as at April 2020 with at least one risk factor.
Of these, 91,546 lived in the community and 11,276 lived in RAC. For communitydwelling older adults, the median age was 80 years (interquartile range [IQR] 73-90 years); 60\% were male. For those in RAC, the median age was 93 years (IQR 90-96 years); 23\% were male. In the previous year, $8 \%$ of DVA clients in the community and $13.6 \%$ in RAC had at least one dispensing of a medication for anxiety, while $29 \%$ and $44 \%$ respectively had at least one dispensing of a medication for depression. The one-year prevalence of treatments for dementia was $1.8 \%$ in the community and $8 \%$ in RAC. In the community cohort, $79 \%$ had at least one risk factor for poor outcomes from COVID-19 in addition to their age (Figure 1). In RAC, $82 \%$ had at least one additional risk factor in addition to age.

Of the individual risk factors, hypertension had the highest prevalence among the community cohort, followed by chronic heart disease, chronic airways disease and diabetes (Figure 2). The RAC cohort had a lower prevalence of hypertension and malignancy but a higher prevalence of chronic conditions including heart disease, airways disease and renal failure.

Overall, over $50 \%$ of the cohort had $\geq 2$ risk factors, and $20 \%$ had $\geq 3$ risk factors for poor outcomes in the event of

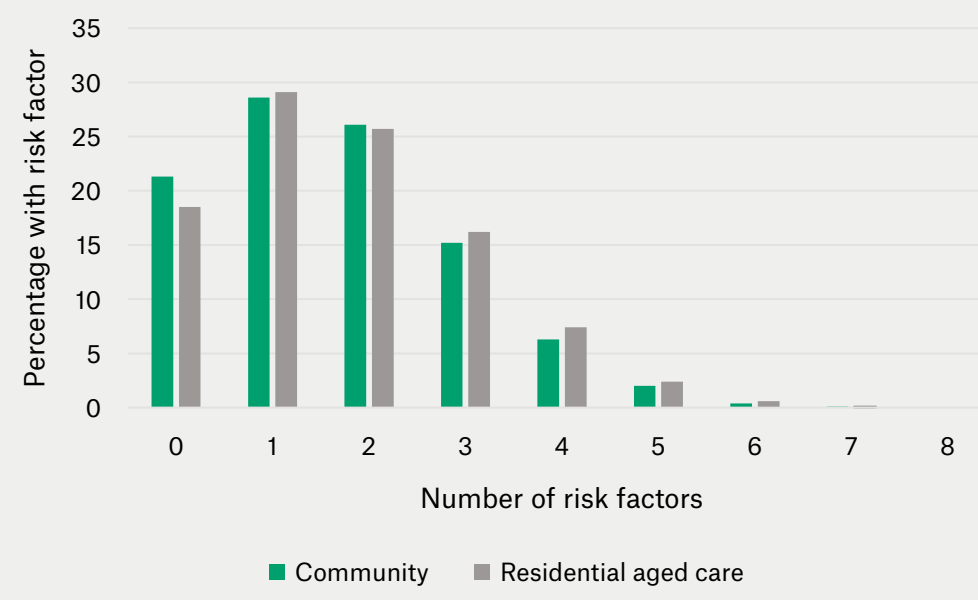

Figure 1. Proportion of veterans with single or multiple risk factors for poor outcomes with COVID-19

COVID-19 infection across multiple body system classes (Table 2). Cardiovascular conditions and comorbid diabetes, respiratory or immune conditions were most prevalent in the community cohort; however, comorbid cardiovascular conditions and respiratory conditions were more frequent in the RAC cohort than in the community cohort. Immunerelated conditions and diabetes were less prevalent in the RAC cohort than in the community cohort.

\section{Discussion}

This study identified that at least $80 \%$ of Australian veterans aged $>70$ years had at least one risk factor that placed them at high risk of poor outcomes due to COVID-19, with frequent multimorbidity of risk factors. One in five patients had $\geq 3$ risk factors across multiple body systems, the most common combination of which was cardiovascular, respiratory and immune-related disease. This group represents one of the multimorbid cohorts likely to be at highest risk of poor outcomes associated with COVID-19. While the number of risk factors was similar between community- and RAC-dwelling patients, there were differences in the composition of those risk factors between the groups. While cardiovascular conditions were the most prevalent in both groups, in community-dwelling patients, the next most prevalent conditions were immunerelated disease and diabetes, which have been shown to be among the most important risk factors for death due to COVID-19. While patients in RAC are more likely to be female, and therefore at lower risk overall, their comorbidity profile included a higher prevalence of chronic conditions of the airways and renal disease, which also place these patients at increased risk. ${ }^{16}$ There were some differences in the prevalence of particular conditions between the communitydwelling veterans and those in RAC. For example, the prevalence of hypertension was $65 \%$ in community-dwelling veterans and $59 \%$ in those in RAC. Chronic airways disease prevalence was $22 \%$ in the community and $29 \%$ in RAC. Individuals in RAC are older and likely sicker, and 
treatment goals are frequently modified in this population. This may explain why fewer people in RAC than the community were treated for hypertension (which is generally asymptomatic), but there was a similar prevalence of treatment for symptomatic conditions such as COPD in community-dwelling and RAC cohorts. In addition to the burden of risk factors for COVID-19, a substantial number of patients were also taking medicines for anxiety and depression, suggesting that these patients may also require additional support to ensure mental wellbeing during and after COVID-19.

The prevalence results found in the present study align with the prevalence of reported conditions among patients admitted to hospital for COVID-19 in other international health systems. ${ }^{18}$ Analysis of the US Veterans Affairs database ${ }^{18}$ showed that for patients admitted for COVID-19, the prevalence of hypertensive disease was 70\%, diabetes was $43 \%$ and COPD was $29 \% .^{18}$ One-quarter of patients in the present study had immune-related conditions, which have been identified as resulting in a proportionately higher risk of death in patients with COVID-19 than other risk factors: ${ }^{16}$ organ transplant (four times higher risk), recent malignancy (1.5-3.5 times higher risk) and taking immunosuppressants (1.7 times higher risk). One-quarter of the population in the present study had diabetes, which has also been shown to be associated with a doubling in the risk of death with COVID-19. ${ }^{19}$

This study is limited by the use of administrative claims data and strict definitions of some conditions, which may have resulted in an underestimate of the prevalence of those conditions. For example, heart failure was defined by hospital admission for heart failure or medications that were limited to subsidisation for heart failure. People with heart failure solely managed by medicines that affect the renin-angiotensin system and diuretics would not be identified using this definition. A strength of the analysis was that the categories were independent, with medicines, services or hospitalisation events only categorised once, thus the estimate of multimorbidity is likely to be robust with a bias to the null, suggesting that the multimorbidity profile is at least this extent but could be greater. While this research was undertaken in the DVA population, if extrapolated to the national population, the results highlight the substantial number of Australians at risk of poor outcomes from COVID-19. A previous comparison of the older DVA population with the Australian population has suggested a similar amount of medicine and health service use in both groups after exclusion of service-related disability. ${ }^{20}$ Some medicines are only subsidised by DVA and not available in the general community. However, the algorithms used in this study only included medicines that are subsidised for both the veteran and non-veteran community, so there is no reason to expect that the results would be different in the general community.

Patients identified in this cohort are likely to be vulnerable to poor outcomes due to both the development of COVID-19 and omission of care should they not seek

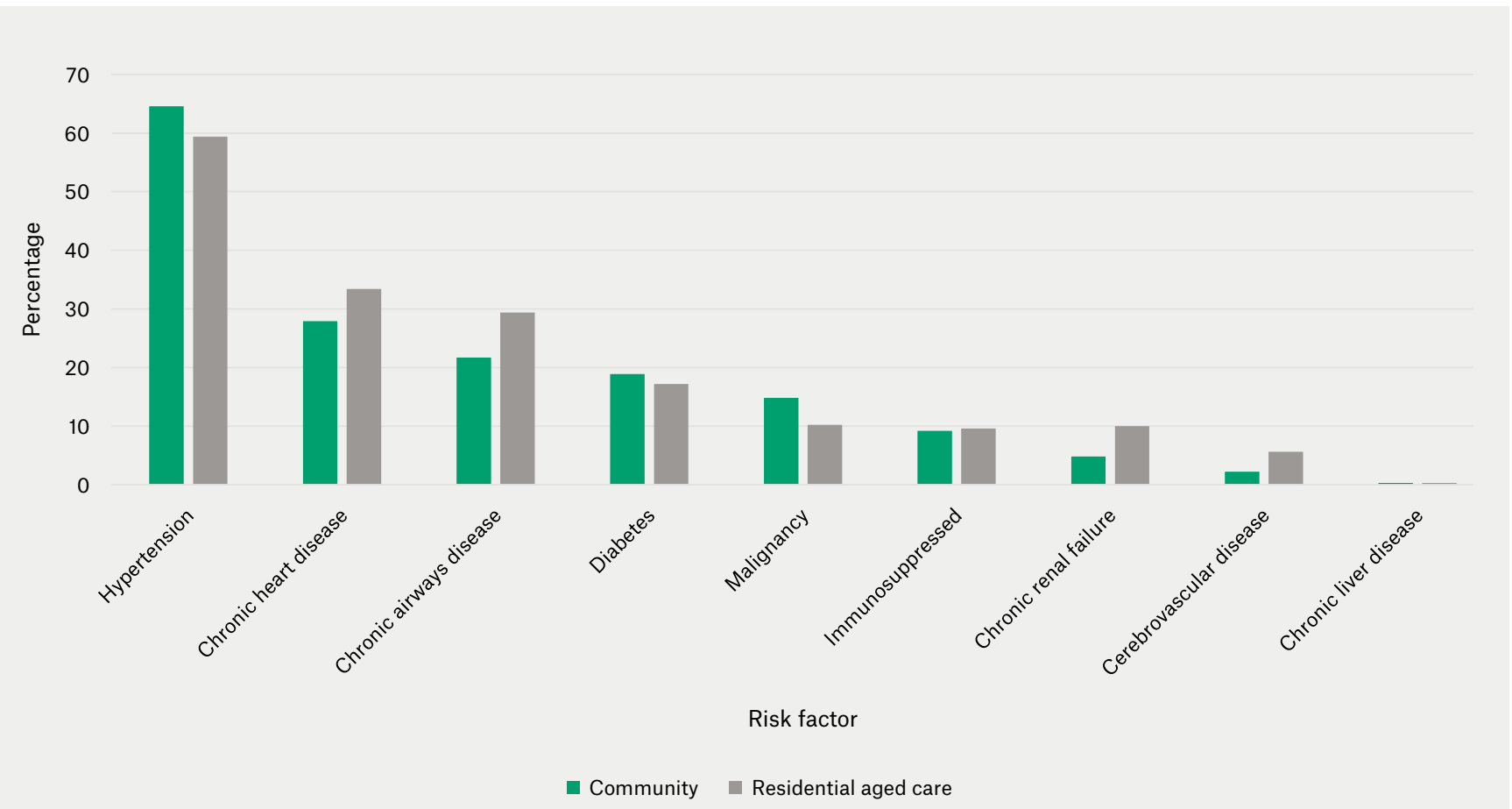

Figure 2. Prevalence of risk factors for poor outcomes with COVID-19 among veterans aged $\geq 70$ years 
or receive appropriate healthcare for their existing conditions during the COVID-19 pandemic. During a health crisis such as the COVID-19 pandemic, public health interventions are critical to ensure that damage as a consequence of infection in vulnerable individuals is minimised. While sometimes overlooked, indirect consequences must also be managed including avoiding health consequences due to omission of healthcare for existing chronic conditions. The identification of such patients may be helpful for prioritising access to federal government initiatives to support high-risk patients to ensure their existing conditions continue to be well managed, including telehealth services where presentation at the medical clinic may not be advised or possible, and delivery services for pharmaceuticals to avoid busy pharmacies. ${ }^{21}$ In addition, many of the medicines frequently used in

\section{Table 2. The multimorbidity profile of veterans at risk of poor outcomes with COVID-19 infections*}

\begin{tabular}{lrrrrr}
\hline Body system class & \multicolumn{2}{c}{ Community } & \multicolumn{2}{c}{ Aged care } \\
\hline Single risk factor & $\mathbf{n}$ & $\%$ & $\mathbf{n}$ & $\%$ \\
\hline Cardiovascular & 27761 & 38.5 & 3487 & 36.0 \\
\hline Immune & 2936 & 4.1 & 258 & 2.7 \\
\hline Respiratory & 1987 & 2.8 & 460 & 4.8 \\
\hline Diabetes & 1398 & 1.9 & 226 & 2.3 \\
\hline
\end{tabular}

Two risk factors

\begin{tabular}{lcccr}
\hline Cardiovascular and diabetes & 7657 & 10.6 & 734 & 7.6 \\
\hline Cardiovascular and respiratory & 7517 & 10.4 & 1322 & 13.7 \\
\hline Cardiovascular and immune & 7337 & 10.2 & 667 & 6.9 \\
\hline Respiratory and immune & 888 & 1.2 & 128 & 1.3 \\
\hline Cardiovascular and renal & 887 & 1.2 & 268 & 2.8 \\
\hline
\end{tabular}

Three risk factors

Cardiovascular and respiratory

\begin{tabular}{lcccc} 
and immune & 3633 & 5.0 & 497 & 5.1 \\
\hline $\begin{array}{l}\text { Cardiovascular and diabetes } \\
\text { and respiratory }\end{array}$ & 2269 & 3.2 & 307 & 3.2 \\
\hline Cardiovascular and diabetes and immune & 2177 & 3.0 & 155 & 1.6 \\
\hline Cardiovascular and diabetes and renal & 697 & 1.0 & 124 & 1.3 \\
\hline Cardiovascular and respiratory and renal & 690 & 1.0 & 209 & 2.2 \\
\hline
\end{tabular}

Four risk factors

Cardiovascular and diabetes and respiratory and immune

1112

474

Cardiovascular and diabetes and respiratory and renal

Cardiovascular and respiratory and renal and immune
421

0.6

*Limited to morbidity profiles prevalent in $\geq 1 \%$ of the population this cohort - including medicines affecting the angiotensin-renin system, nonsteroidal anti-inflammatory agents, and medicines with immunosuppressant properties - have been the subject of media reports ${ }^{22-24}$ suggesting that they might increase the risk of poor outcomes. It is important that patients receiving these medicines are monitored to ensure that they continue to take their medications as directed by their healthcare provider.

In conclusion, these results suggest that a substantial proportion of the older population are at risk of poor outcomes from COVID-19 because of their multimorbid risk profile, with over half having $\geq 2$ of these risk factors. This cohort is also likely to be vulnerable to adverse outcomes if they under-use health services during the COVID-19 pandemic. They are a priority group for ongoing close monitoring and support to ensure they access appropriate health services during the pandemic.

\section{Authors}

NL Pratt PhD, Associate Professor, Quality Use of Medicines and Pharmacy Research Centre, Clinical and Health Sciences, University of South Australia, SA LM Kalisch Ellett PhD, Senior Research Fellow, Quality Use of Medicines and Pharmacy Research Centre, Clinical and Health Sciences, University of South Australia, SA

AQ Andrade PhD, MD, Senior Research Fellow, Quality Use of Medicines and Pharmacy Research Centre Clinical and Health Sciences, University of South Australia, SA

VT Le Blanc BA, Manager, Veterans' MATES, Quality Use of Medicines and Pharmacy Research Centre, Clinical and Health Sciences, University of South Australia, SA

J Barratt GradDip, BAppSci, BPharm, Adjunct Research Fellow, Quality Use of Medicines and Pharmacy Research Centre, Clinical and Health Sciences, University of South Australia, SA EE Roughead PhD, Professor, Quality Use of Medicines and Pharmacy Research Centre, Clinical and Health Sciences, University of South Australia, SA Competing interests: None.

Funding: This study was funded by the Australian Government Department of Veterans' Affairs. The researchers had full access to all relevant data in this study, and supporting sources had no involvement in data analysis and interpretation, or in the writing of the article.

Provenance and peer review: Not commissioned, externally peer reviewed.

Correspondence to:

libby.roughead@unisa.edu.au

\section{References}

1. European Centre for Disease Control and Prevention. Coronavirus disease 2019 (COVID-19) pandemic: Increased transmission in the EU/EEA 
and the UK - seventh update, 25 March 2020. Stockholm, SE: ECDC, 2020.

2. Guan WJ, Ni ZY, Hu Y, et al. Clinical characteristics of coronavirus disease 2019 in China. N Engl J Med 2020;382(18):1708-20. doi: 10.1056/ NEJMoa2002032.

3. Wang $\mathrm{D}, \mathrm{Hu} \mathrm{B}, \mathrm{Hu}$ C, et al. Clinical characteristics of 138 hospitalized patients with 2019 novel coronavirus-infected pneumonia in Wuhan, China. JAMA 2020;323(11):1061-69. doi: 10.01/ jama.2020.1585.

4. Zhou F, Yu T, Du R, et al. Clinical course and risk factors for mortality of adult inpatients with COVID-19 in Wuhan, China: A retrospective cohort study. Lancet 2020;395(10229):1054-62. doi: 10.1016/S0140-6736(20)30566-3.

5. Wu Z, McGoogan JM. Characteristics of and important lessons from the coronavirus disease 2019 (COVID-19) outbreak in China: Summary of a report of 72314 cases from the Chinese center for disease control and prevention. JAMA 2020;323(13):1239-42. doi: 10.1001/ jama.2020.648.

6. Chen $\mathrm{T}, \mathrm{Wu} \mathrm{D}, \mathrm{Chen} \mathrm{H}$, et al. Clinical characteristics of 113 deceased patients with coronavirus disease 2019: Retrospective study. BMJ 2020;368:m1091. doi: 10.1136/bmj.m1091.

7. CDC COVID-19 Response Team. Preliminary estimates of the prevalence of selected underlying health conditions among patients with coronavirus disease 2019 - United States, February 12-March 28, 2020. MMWR Morb Mortal Wkly Rep 2020;69(13):382-86. doi: 10.15585/mmwr.mm6913e2.

8. Guan WJ, Liang WH, Zhao Y, et al. Comorbidity and its impact on 1590 patients with COVID-19 in China: A nationwide analysis. Eur Respir J 2020;55(5):2000547. doi: 10.1183/13993003.00547-2020.

9. Yang $X, Y u Y, X u$ J, et al. Clinical course and outcomes of critically ill patients with SARS-CoV-2 pneumonia in Wuhan, China: A single-centered, retrospective, observational study. Lancet Respir Med 2020;8(5):475-81. doi: 10.1016/S2213-2600(20)30079-5.

10. Verity R, Okell LC, Dorigatti I, et al. Estimates of the severity of coronavirus disease 2019: A model-based analysis. Lancet Infect Dis 2020:20(6):669-77. doi: 10.1016/S14733099(20)30243-7.

11. Liang W, Guan W, Chen R, et al. Cancer patients in SARS-CoV-2 infection: A nationwide analysis in China. Lancet Oncol 2020;21(3):335-37. doi: 10.1016/S1470-2045(20)30096-6.

12. WHO Collaborating Centre for Drug Statistics Methodology. ATC/DDD index 2020. Oslo, NO: World Health Organization Collaborating Centre for Drug Statistics Methodology, 2019. Available at www.whocc.no/atc_ddd_index [Accessed 16 October 2020].

13. Department of Health. MBS online: Medicare benefits schedule. 2020. Canberra, ACT: DoH, 2020. Available at www.mbsonline.gov.au/ internet/mbsonline/publishing.nsf/Content/ Home [Accessed 16 October 2020].

14. Department of Veterans' Affairs. Fees schedules for GPs and specialists. Brisbane, Qld: DVA, 2020 Available at www.dva.gov.au/providers/feesschedules [Accessed 16 October 2020].

15. National Centre for Classification in Health. International statistical classification of diseases and related health problems. 10th revision, Australian Modification (ICD-10-AM). Sydney, NSW: National Centre for Classification in Health, Faculty of Health Sciences, University of Sydney, 2019
16. Williamson E, Walker AJ, Bhaskaran KJ, et al. OpenSAFELY: Factors associated with COVID-19-related hospital death in the linked electronic health records of 17 million adult NHS patients. medRxiv 2020 doi: 10.1101/2020.05.06.20092999. [ePub ahead of print]

17. Pratt NL, Kerr M, Barratt JD, et al. The validity of the Rx-risk comorbidity index using medicines mapped to the Anatomical Therapeutic Chemical (ATC) classification system. BMJ Open 2018;8(4):e021122. doi: 10.1136/bmjopen-2017021122.

18. Burn E, You SC, Sena AG, et al. An international characterisation of patients hospitalised with COVID-19 and a comparison with those previously hospitalised with influenza. medRxiv 2020. doi: 10.1101/2020.04.22.20074336. [ePub ahead of print]

19. Huang I, Lim MA, Pranata R. Diabetes mellitus is associated with increased mortality and severity of disease in COVID-19 pneumonia - A systematic review, meta-analysis, and meta-regression. Diabetes Metab Syndr 2020;14(4):395-403. doi: 10.1016/j.dsx.2020.04.018.

20. Australian Institute of Health and Welfare. Health care usage and costs. A comparison of veterans and war widows and widowers with the rest of the community. Cat. no. PHE 42. Canberra, ACT: AlHW, 2002.

21. Department of Health. Coronavirus (COVID-19): National health plan resources. Canberra, ACT: DoH, 2020 Available at www.health.gov.au/resources/ collections/coronavirus-covid-19-national-healthplan-resources [Accessed 16 October 2020].

22. Fang L, Karakiulakis G, Roth M. Are patients with hypertension and diabetes mellitus at increased risk for COVID-19 infection? Lancet Respir Med 2020;8(4):e21. doi: 10.1016/S2213-2600(20)30116-8.

23. Day M. Covid-19: European drugs agency to review safety of ibuprofen. BMJ 2020;368:m1168. doi: 10.1136/bmj.m1168.

24. Willsher K. Anti-inflammatories may aggravate Covid-19, France advises. The Guardian. 15 March 2020. Available at www.theguardian.com/ world/2020/mar/14/anti-inflammatory-drugsmay-aggravate-coronavirus-infection [Accessed 16 October 2020]. 